\title{
Erosive and cariogenic potential of various pediatric liquid medicaments on primary tooth enamel: A SEM study
}

\section{Erozyjny i próchnicotwórczy potencjał wybranych płynnych leków pediatrycznych w odniesieniu do szkliwa zębów mlecznych - badanie w mikroskopii elektronowej}

\author{
Elham Fathy Mahmoud ${ }^{1, A-D, F}$, Ola Moustafa Omar ${ }^{2, A, C-F}$ \\ ${ }^{1}$ Department of Oral Biology, Faculty of Oral and Dental Medicine, Suez Canal University, Ismailia, Egypt \\ ${ }^{2}$ Department of Pediatric Dentistry, Faculty of Oral and Dental Medicine, Cairo University, Egypt \\ A - research concept and design; $B$ - collection and/or assembly of data; $C$ - data analysis and interpretation; \\ $D$ - writing the article; $E$ - critical revision of the article; $F$ - final approval of the article
}

Address for correspondence

Ola Omar

E-mail: omaromo@yahoo.com

Funding sources

None declared

Conflict of interest

None declared

Received on March 3, 2018 Reviewed on April 25, 2018 Accepted on May 23, 2018

DOI

$10.17219 / \mathrm{dmp} / 91539$

\section{Copyright}

○ 2018 by Wroclaw Medical University

and Polish Dental Society

This is an article distributed under the terms of the

Creative Commons Attribution Non-Commercial License

(http://creativecommons.org/licenses/by-nc-nd/4.0/)

\begin{abstract}
Background. Oral pediatric liquid medications (PLMs) are commonly used in children who suffer from chronic diseases. The physicochemical parameters of PLMs can have a deleterious effect on tooth structure.

Objectives. The purpose of the present study was to investigate the erosive and cariogenic effect of widespread PLMs on the surface roughness and structure of primary tooth enamel.

Material and methods. The erosive potential of 8 common PLMs used in Egypt was assessed by measuring their inherent $\mathrm{pH}$, using a digital pH electrode meter. The total sugar content was measured according to the Fehling method. The erosive effect of each liquid medicine on the enamel surface of primary teeth was assessed using scanning electron microscopy (SEM) and energy dispersive X-ray (EDX) microanalysis for calcium (Ca) and phosphorus (P) content.

Results. Most PLMs revealed an acidic nature, with pH values ranging between 3.47 and 6.92. About $93.8 \%$ of analgesics had pH values $\leq 5.5$, critical for enamel demineralization, whereas most antitussives and 1 antibiotic (Augmentin ${ }^{\circledR}$ ) had pH values $\geq 6.2$. Sucrose was present in all the samples studied. The SEM analysis revealed observable differences in the tooth enamel in the experimental groups, with different degrees of surface roughness and erosion.

Conclusions. The current results suggest that the pH, sugar content and Ca dissolution ability of PLMs can significantly influence erosion in primary tooth enamel.

Key words: scanning electron microscopy, primary teeth, dental erosion, caries, pediatric liquid medications

Słowa kluczowe: skaningowy mikroskop elektronowy, zęby mleczne, erozja zębów, próchnica, płynne leki pediatryczne
\end{abstract}




\section{Introduction}

Dental caries is the most prevalent infectious disease affecting children. This multifactorial disease occurs through the interaction of oral bacteria, carbohydrates, teeth, and time. The production of acids through the fermentation of dietary carbohydrates by the biofilm on tooth surfaces leads to a fall in plaque $\mathrm{pH}$, which results in enamel dissolution and tooth cavitation., ${ }^{1,2}$

Oral pediatric liquid medications (PLMs), such as suspensions, syrups and solutions, are the best line of treatment for younger children. The prolonged use of such liquid medications, particularly in children who suffer from chronic diseases (asthma, respiratory sensitivity and convulsions) or frequent acute conditions (allergic rhinitis, sinusitis, otitis media, and tonsillitis) can have a deleterious effect on tooth structure. $^{3}$

Sugar is added to the majority of oral PLMs to make them palatable and hence acceptable for the child. ${ }^{4}$ Sucrose is the most commonly used sweetener for such medications, as it is an easily processed as well as cost-effective substance. Fructose and glucose are also added to some of these medications. ${ }^{5}$ These sugars, particularly sucrose, act as a substrate for the oral bacteria, which are responsible for their fermentation, leading to the production of acids and a subsequent drop in intraoral pH. ${ }^{6}$

Acids are added to medicines as buffering agents in order to maintain the chemical consistency and regulate the tonicity of the medicines, or to ensure their physiological compatibility. Acids are commonly used to ameliorate flavor. They are necessary for the acidbase reactions that are used in the case of dispersible and effervescent tablets, designed to be added to water. $^{7}$ Since many PLMs have low $\mathrm{pH}$, which is mostly $<5.5$, they can also promote dental erosion. ${ }^{8,9}$

Several studies have investigated the physicochemical parameters of PLMs to determine their cariogenic and erosive potential. Xavier et al. found that all classes of pediatric drugs showed acidic $\mathrm{pH}$ and high total sugar content. ${ }^{10}$ In $47.5 \%$ of the formulations, sucrose was added, as well as citric acid (39.0\%), sodium saccharin (36.4\%) and sorbitol (34.8\%). ${ }^{10}$

In another study, the average value of the endogenous $\mathrm{pH}$ of PLMs was $4.63 \pm 0.57$, ranging between 3.93 and 5.68 , and nearly all (93.8\%) analgesics had $\mathrm{pH}$ values $\leq 5.5$. In $11(68.75 \%)$ analgesics, sugars were revealed and the sugar content ranged from 5.38 to $69.4 \mathrm{~g} \%$, with a mean concentration of $24.97 \pm 23.24 \mathrm{~g} \%{ }^{11}$

Gupta and Panda also found that PLMs had $\mathrm{pH}$ values extending from 4.22 to 6.10. Most PLMs included sucrose at the concentration of $5.38-11.41 \mathrm{~g} \% .^{12}$

Pediatric liquid medications are potentially erosive and cariogenic due to low $\mathrm{pH}$, high total sugar content and high viscosity. Furthermore, many studies have shown a positive association between the habitual intake of these drugs and the prevalence of dental caries, which represents a major children's oral health concern, leaving children with chronic or recurrent health problems, who take PLMs frequently or in long-term treatment, at a high risk. ${ }^{5,11,13-15}$

Few studies have investigated the effect of PLMs on the enamel structure. Babu et al. concluded that all the PLMs used in their study revealed an erosive effect on the primary teeth enamel surface, regardless of their $\mathrm{pH}$, when examined under a scanning electron microscope $(\mathrm{SEM}) .^{3}$ An atypical bore-like erosion area was observed in all specimens, differing from one site to another, which could be due to the prismatic nature and structure of the influenced enamel. ${ }^{3}$

For these reasons, the current study aimed to investigate and compare the cariogenic and erosive effect of the PLMs most commonly prescribed in Egypt on primary tooth enamel. The endogenous $\mathrm{pH}$ value of PLMs, as well as the concentration of sugars in them, were also evaluated, as they can be indicative of their cariogenic and erosive potential.

\section{Material and methods}

The 8 different PLMs that are most commonly used in Egypt were selected for this study. The PLMs included usually prescribed analgesics and antipyretics, antibiotics, antitussive drugs, and nutritional supplements (Table 1). Their endogenous $\mathrm{pH}$ was determined using a $\mathrm{pH}$ electrode meter, and the Fehling method was used to measure the total sugar content.

The erosive effect of each liquid medicine on primary tooth enamel was assessed by SEM. Specimens were prepared from 50 extracted or exfoliated sound primary teeth free from any carious lesion and/or restorations. Enamel specimens were cut at the dentinenamel junction, and the samples were placed in Teflon molds and embedded in self-curing acrylic resin (Paladur 1; Heraeus Kulzer, Bad Homburg v. d. Höhe, Germany), exposing approx. $2 \mathrm{~mm} \times 2 \mathrm{~mm}$ of the buccal surface, parallel to the bottom of the mold.

The control group tooth samples $(n=10)$ were immersed in artificial saliva (Pickering Laboratories, Mountain View, USA) for 3 different time intervals: 3,5 and 8 days, $20 \mathrm{~min}$ for each session. The study group tooth samples $(n=40)$ were also maintained for 3 different time intervals: 3,5 and 8 days, $20 \mathrm{~min}$ for each session, in the various selected PLMs, and then immersed in artificial saliva to apply a $\mathrm{pH}$ circulation model for the rest. Primary tooth specimens were observed under a SEM after each time interval. 
Table 1. The $\mathrm{pH}$ values of PLMs and sucrose concentration in different samples

\begin{tabular}{|c|c|c|c|c|}
\hline PLMs & Generic name & Trade name & Mean pH & $\begin{array}{c}\text { Concentration of sucrose } \\
[\mathrm{g} \%] \text { (mean } \pm \mathrm{SD})\end{array}$ \\
\hline \multirow{2}{*}{ Analgesics } & paracetamol & $\mathrm{Ado}^{\circledR}$ & 5.33 & $16.02 \pm 0.01$ \\
\hline & ibuprofen & Brufen $^{\circledR}$ & 4.42 & $9.08 \pm 0.03$ \\
\hline \multirow{2}{*}{ Antibiotics } & amoxicillin & Amoxil $^{\circledR}$ & 5.68 & $11.04 \pm 0.06$ \\
\hline & amoxicillin + clavulanate potassium & Augmentin ${ }^{\circledR}$ & 6.22 & $3.17 \pm 0.04^{*}$ \\
\hline \multirow{2}{*}{ Nutritional supplements } & multivitamin & Vitamount ${ }^{\circledR}$ & $3.47^{*}$ & $17.18 \pm 1.05^{*}$ \\
\hline & multivitamin & Omega-3 ${ }^{\circledR}$ & 4.01 & $8.22 \pm 0.21$ \\
\hline \multirow[t]{2}{*}{ Antitussives } & $\begin{array}{c}\text { dextromethorphan } \\
\text { diphenhydramine } \mathrm{HCl} \\
\text { ephedrine } \mathrm{HCl} \\
\text { guaiphenesin }\end{array}$ & Bronchophane $^{\circledR}$ & 6.74 & $7.01 \pm 2.03$ \\
\hline & oxomemazine/guaiphenesin & Toplexil N ${ }^{\circledR}$ & $6.92^{*}$ & $9.04 \pm 0.02$ \\
\hline
\end{tabular}

PLMs - pediatric liquid medications; SD - standard deviation; * the highest amount of sucrose.

\section{Measurement of $\mathrm{pH}$}

The $\mathrm{pH}$ of the PLMs was measured using a digital $\mathrm{pH}$ meter (Hanna Instruments, Woonsocket, USA). The amount of $20 \mathrm{~mL}$ of each PLM in a glass beaker was placed in a water bath thermostatically controlled at $37^{\circ} \mathrm{C}$. A glass electrode was inserted into the syrup, displaying $\mathrm{pH}$ on the meter. Each sample was tested 3 times to record a mean measurement.

\section{Measurement of total sugar content}

The Fehling method was used for total sugar content determination in the PLM samples used in this study. ${ }^{\text {acc. } 16}$ The total sugar percentage was calculated from the following equation:

$$
\text { Total sugars }[\%]=\frac{\text { FEQ } \times \text { dilution } \times 100}{\text { VTITRATION }}
$$

where:

FEQ - equivalence factor;

VTITRATION - titration volume required.

\section{Observation with scanning electron microscopy and energy dispersive X-ray microanalysis}

For the SEM examination, the teeth were mounted on the SEM holder using removable adhesive. Each tooth was coated under vacuum conditions with gold by means of a sputter coater and adjusted to be examined under low vacuum using a SEM (SEM JEOL-JSM ${ }^{\circledR}$ 6360LV; Japan Electron Optics Laboratory Co., Ltd., Tokyo, Japan) at the SEM Unit, National Research Center, Cairo, Egypt. The surface morphology of the collected teeth was evaluated, and representative photomicrographs were captured and stored digitally. The analysis of the calcium (Ca) and phosphorus $(\mathrm{P})$ content in wt\% of enamel was additionally determined in each group using energy dispersive X-ray (EDX) microanalysis at the SEM Unit.

\section{Statistical analysis}

The results of the EDX microanalysis were used to determine the $\mathrm{Ca}$ and $\mathrm{P}$ content in wt\% of enamel in all groups. The $\mathrm{Ca}$ and $\mathrm{P}$ content were then converted into $\mathrm{Ca} / \mathrm{P}$ ratios, which reflect the level of mineralization of teeth. Collecting, coding and analyzing the obtained data were done with The Statistical Package for the Social Sciences (SPSS) software v. 20 (SPSS Inc., Chicago, USA) for Windows 7. The inferential statistics were done after the descriptive analysis, followed by the analysis of variance (ANOVA, F-test) to compare the mean content of $\mathrm{Ca}$ and $\mathrm{P}$, and $\mathrm{Ca} / \mathrm{P}$ ratios in the study groups. Then, the least significant difference (LSD) post hoc test was done to compare the 2 groups. A cut-off point of 0.05 was established for the p-value.

\section{Results}

Most PLMs revealed an acidic nature, with $\mathrm{pH}$ values ranging between 3.47 and 6.92. Most of the analgesics, about $93.8 \%$, had $\mathrm{pH}$ values $\leq 5.5$, critical for enamel dissolution, whereas most antitussives and the antibiotic Augmentin ${ }^{\circledR}$ had $\mathrm{pH}$ values $\geq 6.2$. Sucrose was present in all the samples and the multivitamin drug Vitamount ${ }^{\circledR}$ contained the highest amount of sucrose $(17.18 \pm 1.05 \mathrm{~g} \%)$. The concentration of sucrose in the samples studied is given in Table 1. 


\section{Observation of primary tooth enamel with scanning electron microscopy and energy dispersive X-ray microanalysis}

In general, the SEM analysis revealed observable differences in the tooth enamel in the experimental groups, with different degrees of surface roughness and erosion. The primary teeth specimens submerged in artificial saliva (the control group I) showed an intact, relatively flat and smooth enamel surface with no morphological irregularities and no evidence of erosion after 3, 5 and 8 days (Fig. 1). The specimens immersed in analgesic PLMs (group II) showed a mildly roughened enamel surface with minimal surface loss after 3 days; then, incremental zones of porosity and intraprismatic dissolution with a fish-scale appearance occurred on the enamel surface after 5 and 8 days (Fig. 2).

The enamel surface of the primary teeth specimens that were submerged in antibiotic PLMs (group III) revealed an irregular, pitted and rough, damaged, cracked surface, having numerous pores of different size and depth (Fig. 3).
The specimens that were immersed in multivitamin PLMs (group IV) revealed a severely irregular, rough, damaged enamel surface with a fish-scale appearance, having multiple craters with elevated peripheries. Some areas of dentin were exposed, being the evidence of generalized structure loss (Fig. 4).

The examination of the specimens exposed to antitussive PLMs (group V) revealed a relatively smooth enamel surface with little porosity and minimal surface loss, with no evidence of erosion even after 8 days (Fig. 5).

The comparison of the element content within the groups using one-way ANOVA revealed statistically highly significant differences in regard to $\mathrm{Ca}, \mathrm{P}$ and $\mathrm{Ca} / \mathrm{P}$ ratios between all groups (Table 2). For intergroup comparison, the results of the post hoc test suggested that the $\mathrm{Ca}$ and $\mathrm{P}$ content were significantly lower in the antibiotic PLMs group III and multivitamin PLMs group IV as compared to the control group. The antitussive PLMs group V showed similar Ca content and higher P content compared to the control group. All statistical results are summarized in Table 3.
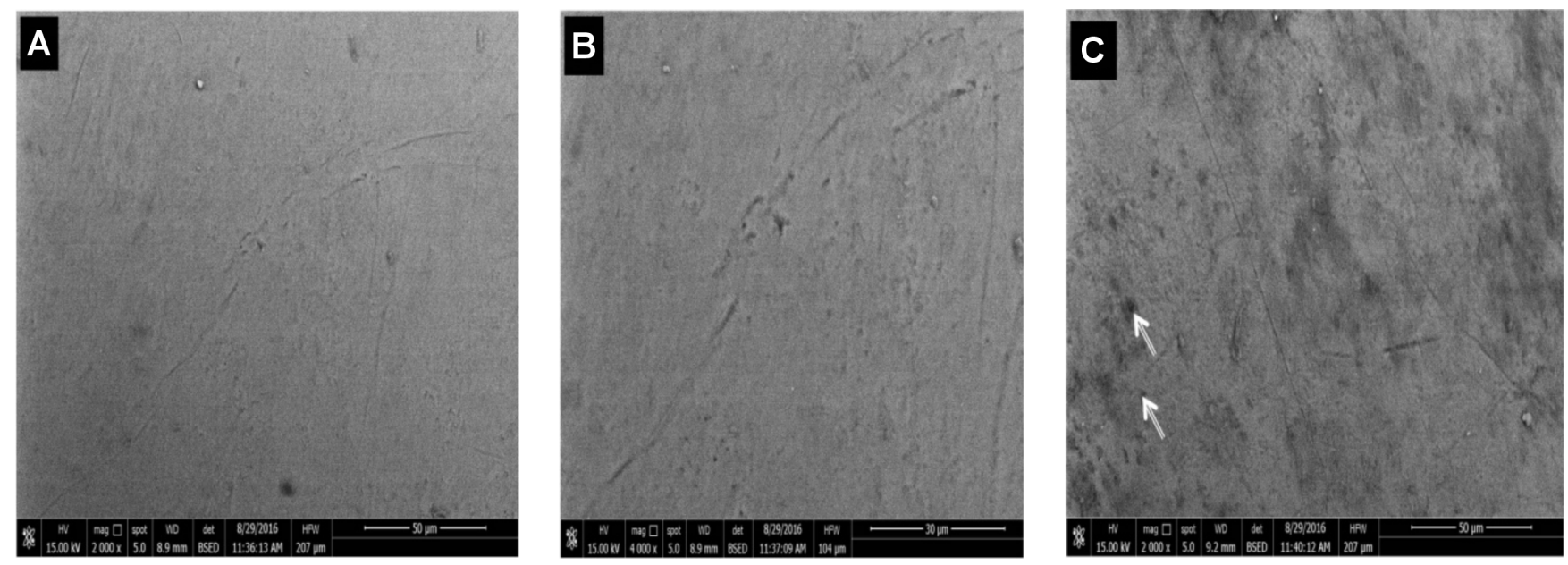

Fig. 1. Scanning electron micrograph of the enamel surface in group I (control): a smooth, intact enamel surface with no evidence of erosion ( $A, B$ ); characteristic minute depressions representing rod ends (arrows) (C)
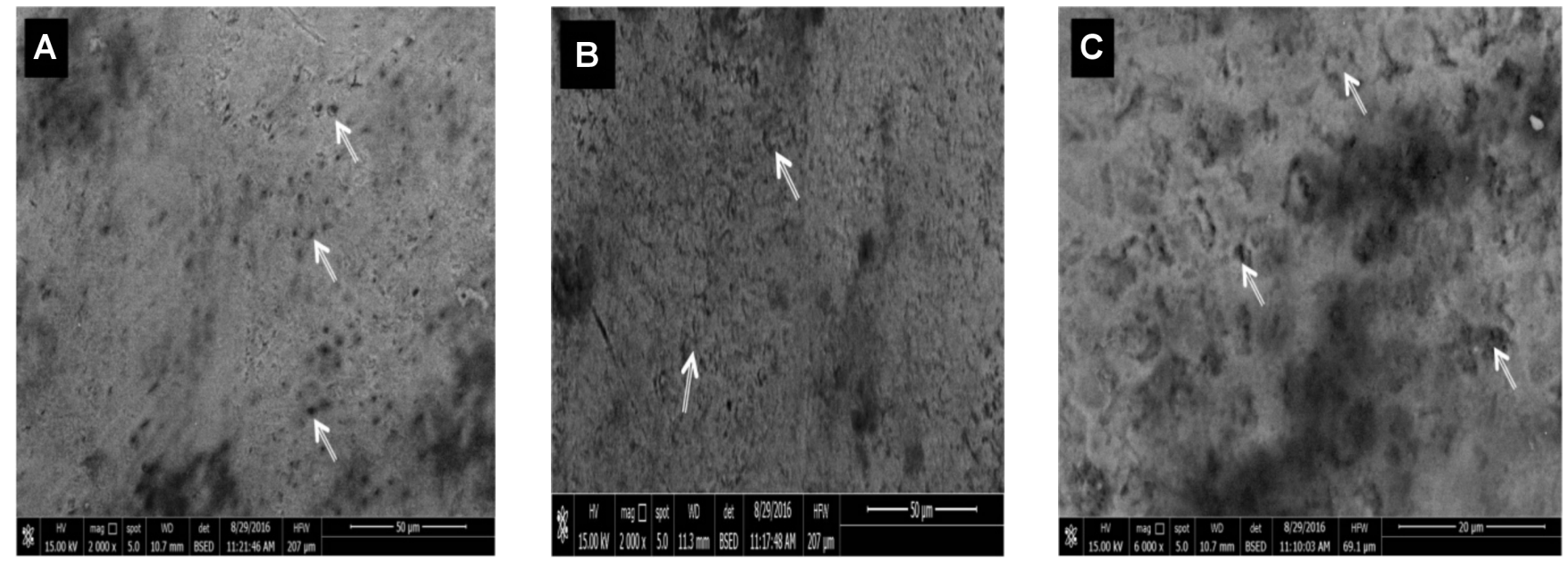

Fig. 2. Scanning electron micrograph of the enamel surface of group II (analgesic PLMs) showing zones of porosity and intraprismatic dissolution with a fish-scale appearance (arrows)

PLMs - pediatric liquid medications. 



Fig. 3. Scanning electron micrograph of the enamel surface of group III (antibiotic PLMs): an irregular, pitted and rough surface (arrows) (A); a rough, damaged, cracked surface (white arrows), having numerous pores of different size and depth (black arrows) (B, C)

PLMs - pediatric liquid medications.
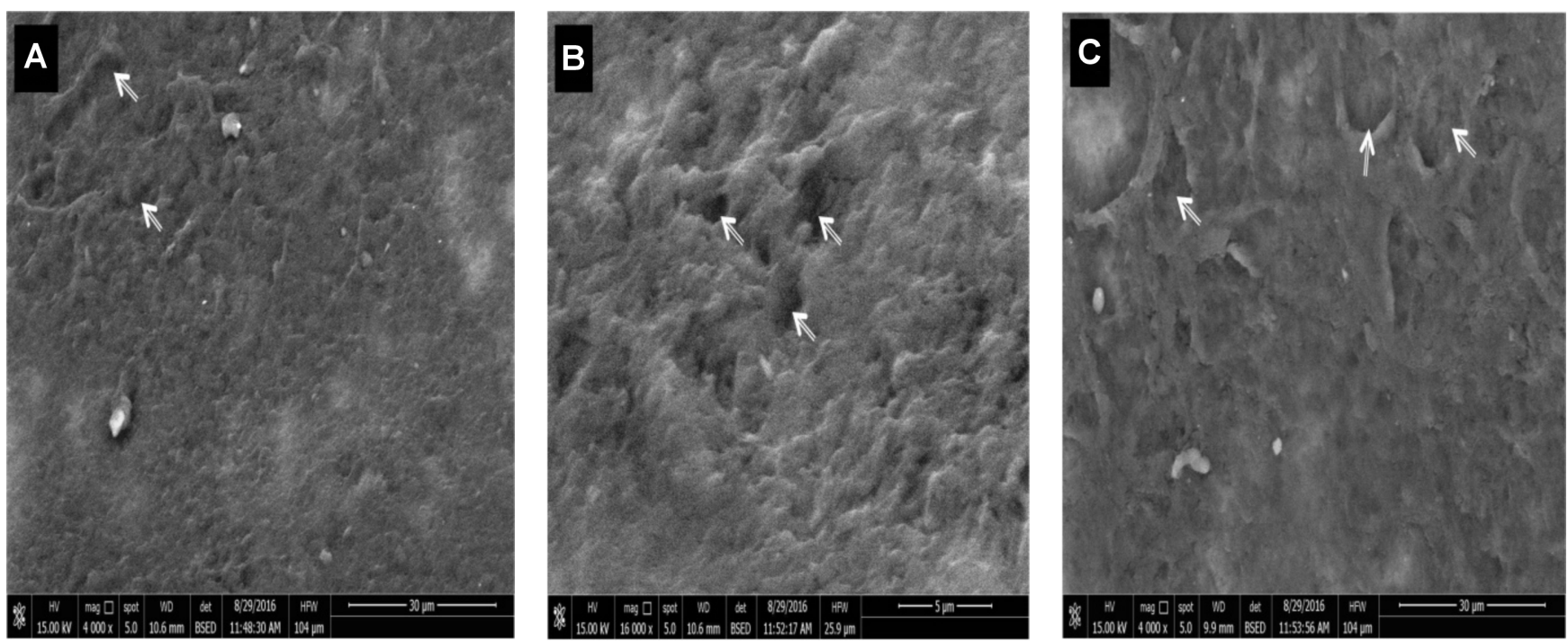

Fig. 4. Scanning electron micrograph of the enamel surface of group IV (multivitamin PLMs): an irregular, rough, damaged enamel surface, having multiple craters with elevated peripheries and some areas of dentin exposed (arrows) (A, B); (D3) the enamel surface roughness and generalized structure loss, and some areas in the enamel surface with a fish-scale appearance (arrows) (C)

PLMs - pediatric liquid medications.
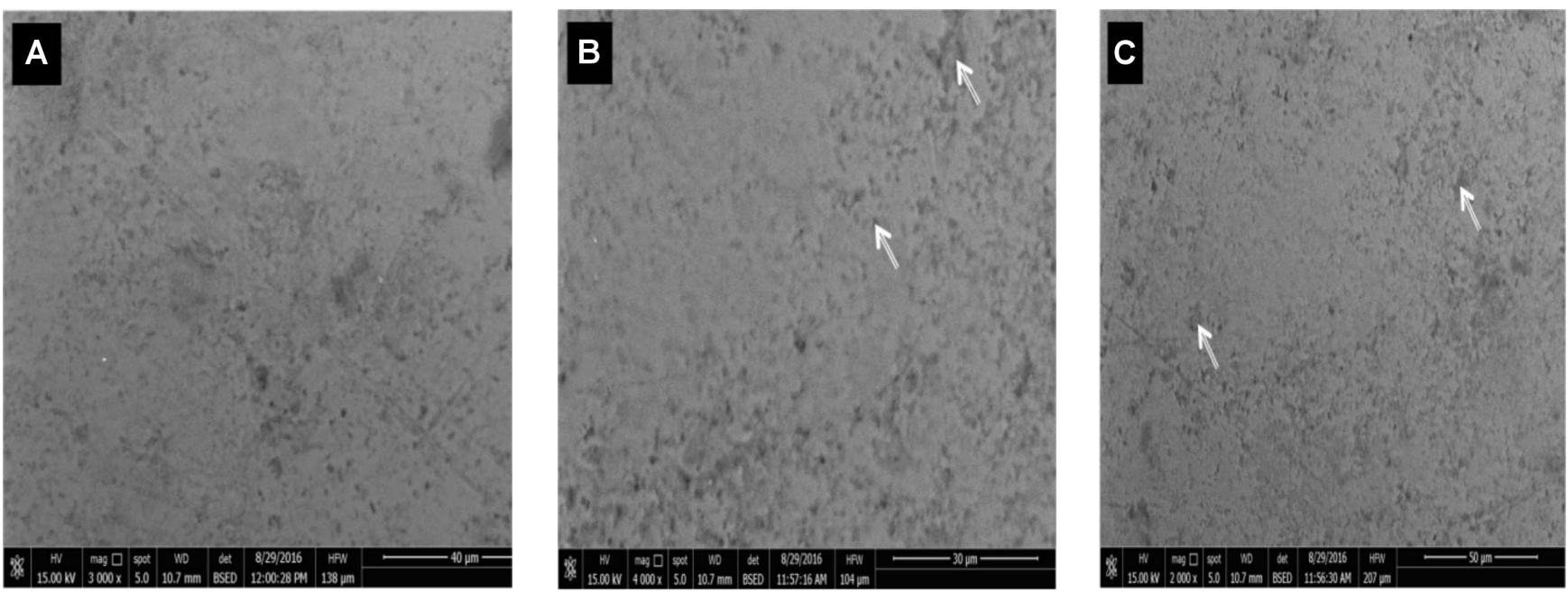

Fig. 5. Scanning electron micrograph of the enamel surface of group V (antitussive PLMs) showing a smooth enamel surface with little porosity, with no evidence of erosion (arrows)

PLMs - pediatric liquid medications. 
Table 2. Comparison of the mean calcium (Ca) and phosphorus (P) content [wt\%], and Ca/P ratios of all groups, using one-way ANOVA

\begin{tabular}{|c|c|c|c|c|}
\hline Group & Value & $\mathrm{Ca}$ & $P$ & $\mathrm{Ca} / \mathrm{P}$ ratio \\
\hline \multirow{2}{*}{ Group I } & mean & 48.861 & 22.413 & 2.180 \\
\hline & $\pm \mathrm{SD}$ & \pm 0.587 & \pm 0.759 & \pm 0.211 \\
\hline \multirow{2}{*}{ Group II } & mean & 35.961 & 16.734 & 2.149 \\
\hline & $\pm \mathrm{SD}$ & \pm 1.001 & \pm 0.103 & \pm 0.211 \\
\hline \multirow{2}{*}{ Group III } & mean & 30.853 & 13.012 & 2.371 \\
\hline & $\pm \mathrm{SD}$ & \pm 0.691 & \pm 0.843 & \pm 0.101 \\
\hline \multirow{2}{*}{ Group IV } & mean & 27.801 & 10.762 & 2.583 \\
\hline & $\pm \mathrm{SD}$ & \pm 0.806 & \pm 0.419 & \pm 0.738 \\
\hline \multirow{2}{*}{ Group V } & mean & 47.922 & 23.639 & 1.985 \\
\hline & $\pm \mathrm{SD}$ & \pm 0.902 & \pm 0.839 & \pm 0.216 \\
\hline \multicolumn{2}{|c|}{ ANOVA } & 231.468 & 112.122 & 21.254 \\
\hline \multicolumn{2}{|c|}{$p$-value } & $\begin{array}{c}0.000 \\
\text { highly significant }\end{array}$ & $\begin{array}{c}0.000 \\
\text { highly significant }\end{array}$ & $\begin{array}{c}0.000 \\
\text { highly significant }\end{array}$ \\
\hline
\end{tabular}

Group I - control; group II - analgesic PLMs; group III - antibiotic PLMs; group IV - multivitamin PLMs; group V - antitussive PLMs; PLMs - pediatric liquid medications; SD - standard deviation; ANOVA - analysis of variance.

Table 3. Intergroup comparison of calcium (Ca) and phosphorus (P) content [wt $\%]$, and Ca/P ratios using the post hoc test

\begin{tabular}{|l|l|l|l|}
$\begin{array}{c}\text { Dependent } \\
\text { variable }\end{array}$ & Control group & Other groups & p-value \\
\hline \multirow{2}{*}{ Ca } & group I & group II & $0.000^{*}$ \\
& & group III & $0.000^{*}$ \\
& & group IV & $0.000^{*}$ \\
\hline \multirow{2}{*}{ P } & group I & group II & 0.832 \\
& & group III & $0.000^{*}$ \\
& & group IV & $0.000^{*}$ \\
& & group V & $0.000^{*}$ \\
\hline \multirow{2}{*}{ Ca/P ratio } & group I & group III & 0.672 \\
& & group IV & $0.000^{*}$ \\
& & group V & 0.713 \\
\hline
\end{tabular}

Group I - control; group II - analgesic PLMs; group III - antibiotic PLMs; group IV - multivitamin PLMs; group V - antitussive PLMs; PLMs - pediatric liquid medications; * a statistically significant difference $(p<0.05)$ among group I and groups II \& III \& IV $(n=10)$, where the post hoc test was used for intergroup comparison.

\section{Discussion}

In spite of a large number of studies on dental erosion, there is still a deficiency of information regarding the erosive influence of PLMs on primary teeth. In the present study, we investigated the erosive effect of various PLMs on primary tooth enamel.

Pediatric liquid medications may possess a high erosive potential due to the presence of an acid component in their formula. Therefore, the analysis of their $\mathrm{pH}$ is an important factor when studying dental erosion. The findings of our study showed that the $\mathrm{pH}$ of the studied medications ranged between 3.47 and 6.92, with multivitamins followed by analgesics having the lowest $\mathrm{pH}$ values. This range was similar to the findings of Gupta and Panda, where the $\mathrm{pH}$ of the studied medications ranged from 4.22 to $6.10 .{ }^{12}$ Our results are also in agreement with other studies, where the $\mathrm{pH}$ of PLMs ranged from 2.5 to $6.9 .{ }^{17,18}$ Furthermore, another study found that the $\mathrm{pH}$ of most of the investigated medications were $<5.5 .^{10} \mathrm{~A} \mathrm{pH}$ of 5.5 is considered critical for enamel dissolution. ${ }^{19}$ In an in vivo study, it was concluded that PLMs cause a drop in plaque $\mathrm{pH}$ sufficient to cause decalcification within 2-10 min following the initial exposure of teeth to those medicaments. ${ }^{20}$ Multivitamins and analgesics are widely used by children, usually without medical supervision; therefore, children using these drugs will most probably experience a deleterious accumulative effect that might lead to erosive and carious lesions on the tooth enamel surface.

Sugars are commonly added to oral liquid medications to give them a pleasant taste. ${ }^{17}$ Sugar-rich medicines cause a drop in the $\mathrm{pH}$ of dental plaque, increasing the risk of demineralization. ${ }^{21}$ Pediatric medicines including sucrose and/or other fermentable carbohydrates and having low $\mathrm{pH}$ display cariogenic and erosive effects. Other factors are also noted, e.g., frequency of administration, dose and pattern of use, as well as acidity of the formulation. ${ }^{22,23}$ All the medicines tested in the present study contained sucrose, with mean concentrations varying from 3.17 to $17.18 \mathrm{~g} \%$, which is in accordance with various studies. Similarly, all the PLMs in a study by Gupta and Panda contained sucrose and it ranged from 5.38 to $11.41 \mathrm{~g} \% .^{12}$ On the other hand, our results are lower compared to those reported in other studies, where not all the studied PLMs contained sugars. Other authors noted that the amount of sucrose in PLMs ranged from 0 to $67 \mathrm{~g} \%{ }^{15}$ Some studies showed a wider range of sugar content, where the concentrations varied from 11.36 to $85.99 \mathrm{~g} \%{ }^{24}$ from 5 to $54 \mathrm{~g} \%{ }^{8}$ and from 5.38 to $69.4 \mathrm{~g} \%{ }^{11}$ Additionally, higher percentages were observed by some authors, ranging from 53.2 to $86.9 \mathrm{~g} \% .^{10,17}$ Differences in 
sugar concentration between studies might be attributed to the method of sugar identification; in the current study, we used the Fehling method for total sugar content determination.

All the PLMs tested in this study showed an erosive effect on the primary enamel surface, irrespective of their $\mathrm{pH}$, when viewed under a SEM. Although antibiotics showed $\mathrm{pH}$ of 5.68 and 6.22, which were slightly higher than the $\mathrm{pH}$ value critical for enamel, under a SEM the enamel specimens exposed to antibiotics showed an irregular, pitted and rough surface with numerous pores of different size and depth. These results are in agreement with other studies, which showed that although the $\mathrm{pH}$ of the PLMs was not near the critical value, erosion was observable on the enamel surfaces during SEM examination. ${ }^{3,25}$ Furthermore, specimens immersed in multivitamin PLMs (group IV) revealed a severely irregular, rough, damaged enamel surface with areas of exposed dentin being the evidence of generalized structural loss, which indicated high erosive potential of these medications. Other studies reported similar typical prism patterns on enamel surfaces treated with amoxicillin for $1 \mathrm{~min}$, theophylline for $1 \mathrm{~min}$ and multivitamin for $10 \mathrm{~min}^{3}$ Similar results were also reported in the cases where the specimens exposed to ferrous sulfate (an iron supplement) and salbutamol sulfate (a bronchodilator) clearly exhibited structural enamel loss with an irregular enamel surface. ${ }^{26}$

The SEM results of our study can be explained by the fact that primary teeth are more liable to erosion, as they are known to be less mineralized than permanent teeth, and the enamel surface is also less mature and thus more prone to dental caries and erosion. ${ }^{27}$

Tooth enamel is composed of calcium $\left(\mathrm{Ca}^{2+}\right)$, phosphate $\left(\mathrm{PO}_{4}{ }^{3-}\right)$, hydroxide $\left(\mathrm{OH}^{-}\right)$, and minimal amounts of fluoride $\left(\mathrm{F}^{-}\right)$ions. Enamel crystals are in a persistent balance with the saliva, where a constant substitution of $\mathrm{Ca}^{2+}, \mathrm{PO}_{4}{ }^{3-}, \mathrm{OH}^{-}$, and $\mathrm{F}^{-}$between enamel and the saliva takes place. Enamel is likely to lose more of these ions to the surrounding medium in order to acquire a new state of equilibrium when the teeth are subjected to substances that have a low concentration of these ions. ${ }^{28}$ Furthermore, the dissolution of enamel is highly dependent on the $\mathrm{pH}$ of the substance surrounding it. ${ }^{29,30}$ That is why, in our study, the $\mathrm{pH}$ analysis played a significant role in the assessment of the dental erosion process, which was also reported by West et al. ${ }^{31}$

All the PLMs used in the current work demonstrated calcium dissolution, with the maximum amount of dissolution at the 8-day interval, followed by the 5-day and 3-day intervals. Similar results were obtained in a study performed by Hunter et al. ${ }^{32}$ The analysis of the results revealed a significantly lower $\mathrm{Ca}$ and $\mathrm{P}$ content of all groups studied compared to the control, except group V (antitussives). A higher $\mathrm{Ca}$ concentration in a given solution increases its degree of saturation, which consequently decreases its erosive effect. ${ }^{33}$ This statement explains our findings, where group V showed a smooth enamel surface with no evidence of erosion and with little porosity observable under a SEM, which was coupled with high Ca content in this group, similar to that noted for the control group. Moreover, similar results showed that $\mathrm{Ca}$ ions are dissolved from the hydroxyapatite before phosphate ions, thus explaining the relationship between Ca concentration and erosion, and the lack of association between phosphate concentration and erosion. ${ }^{34}$

\section{Conclusions}

The current study emphasizes the positive association between PLMs and erosion and/or dental caries, which is deleterious to children's oral health.

\section{Recommendations}

Parents should be strictly advised to apply oral hygiene measures for their children after each therapeutic dose of PLMs. Sugar-free medications (or with non-cariogenic artificial sweeteners) should be suggested. Administering PLMs with a dropper hinders the contact of such medications with the tooth surfaces.

\section{References}

1. Sharma A, Deshpande S. Effect of sucrose in different commonly used pediatric medicines upon plaque $\mathrm{pH}$ in human subjects. $J$ Ind Soc Pedod Prev Dent. 2011;29(2):144-148.

2. Lussi A, Megert B, Shellis RP, Wang X. Analysis of the erosive effect of different dietary substances and medications. Br J Nutr. 2012;107(2):252-262.

3. Babu KL, Rai K, Hedge AM. Pediatric liquid medicaments: Do they erode the teeth surface? An in vitro study: Part I. J Clin Pediatr Dent. 2008;32(3):189-194.

4. Nunn JH, Ng SK, Sharkey I, Coulthard M. The dental implications of chronic use of acidic medicines in medically compromised children. Pharm World Sci. 2001;23(3):118-129.

5. Bigeard L. The role of medication and sugars in pediatric dental patients. Dent Clin North Am. 2000;44(3):443-456.

6. Pierro VS, Abdelnur JP, Maia LC, Trugo LC. Free sugar concentration and $\mathrm{pH}$ of paediatric medicines in Brazil. Community Dent Health. 2005;22(3):180-183.

7. Maguire A, Baqir W, Nunn JH. Are sugars-free medicines more erosive than sugars containing medicines? An in vitro study of paediatric medicines with prolonged oral clearance used regularly and long-term by children. Int J Paediatr Dent. 2007;17(4):231-238.

8. Pomarico L, Czauski G, Portela MB, et al. Cariogenic and erosive potential of the medication used by HIV-infected children: $\mathrm{pH}$ and sugar concentration. Community Dent Health. 2008;25(3):170-172.

9. Nankar M, Walimbe H, Ahmed Bijle MN, Kontham U, Kamath A, Muchandi S. Comparative evaluation of cariogenic and erosive potential of commonly prescribed pediatric liquid medicaments: An in vitro study. J Contemp Dent Pract. 2014;15(1):20-25.

10. Xavier AFC, Moura EF, Azevedo WF, Vieira FF, Abreu MH, Cavalcanti AL. Erosive and cariogenicity potential of pediatric drugs: Study of physicochemical parameters. BMC Oral Health. 2013;13:71.

11. Saeed S, Bshara N, Trak J, Mahmoud G. An in vitro analysis of the cariogenic and erosive potential of pediatric liquid analgesics. J Indian Soc Pedod Prev Dent. 2015;33(2):143-146.

12. Gupta M, Panda S. Cariogenic potential of the commonly prescribed pediatric liquid medicaments in the Kingdom of Saudi Arabia: An in vitro study. J Contemp Dent Pract. 2017;18(4):307-311. 
13. Shaw L, Glenwright HD. The role of medications in dental caries formation: Need for sugar-free medication for children. Paediatrician. 1989;16(3-4):153-155.

14. Neves BG, Pierro VS, Maia LC. Perceptions and attitudes among parents and guardians on the use of pediatric medicines and their cariogenic and erosive potential [in Portuguese]. Cien Saude Colet. 2007;12(5):1295-1300.

15. Peres KG, Oliveira CT, Peres MA, Raymundo Mdos S, Fett R. Sugar content in liquid oral medicines for children. Rev Saude Publica. 2005;39(3):486-489.

16. Lane JH, Eynon L. Determination of reducing sugars by means of Fehling's solution with methylene blue as internal indicator. J Soc Chem Ind Trans. 1923:32-36. Cited from: Cavalcanti AL, Sousa RIM, Clementino MA, Vieira FF, Cavalcanti CL, Xavier AFC. In vitro analysis of the cariogenic and erosive potential of paediatric antitussive liquid oral medications. Tanzan J Health Res. 2012;14(2):1-8.

17. Cavalcanti AL, Sousa RIM, Clementino MA, Vieira FF, Cavalcanti CL, Xavier AFC. In vitro analysis of the cariogenic and erosive potential of paediatric antitussive liquid oral medications. Tanzan J Health Res. 2012;14(2):1-8.

18. Passos IA, Sampaio FC, Martínez CR, Freitas CHM. Sucrose concentration and $\mathrm{pH}$ in liquid oral pediatric medicines of long-term use for children. Rev Panam Salud Publica. 2010;27(2):132-137.

19. Cavalcanti AL, Fernandes LV, Barbosa AS, Vieira FF. pH, titratable acidity and total soluble solid content of pediatric antitussive medicines. Acta Stomatol Croat. 2008;42(2):164-170.

20. Sunitha S, Prashanth GM, Shanmukhappa, Chandu GN, Subba Reddy VV. An analysis of concentration of sucrose, endogenous $\mathrm{pH}$, and alteration in the plaque $\mathrm{pH}$ on consumption of commonly used liquid pediatric medicines. $J$ Indian Soc Pedod Prev Dent. 2009;27(1):44-48.

21. Rekola M. In vivo acid production from medicines in syrup form. Caries Res. 1989;23(6):412-416.

22. Costa CC, Almeida IC, Raymundo MS, Fett R. Analysis of the endogenous $\mathrm{pH}$, acidity and sucrose concentration in pediatric medicines. Rev Odonto Ciênc. 2004;19:164-169.

23. Marquezan M, Marquezan M, Pozzobon RT, Oliveira MDM. Medicines used by pediatric dentistry patients and its cariogenic potential. RPG Rev Pós Grad. 2007;13(4):334-339.

24. Neves BG, Farah A, Lucas E, Sousa VP, Maia LC. Are paediatric medicines risk factors for dental caries and dental erosion? Community Dent Health. 2010;27(1):46-51.

25. Tupalli AR, Satish B, Shetty BR, Battu S, Kumar JP, Nagaraju B. Evaluation of the erosive potential of various pediatric liquid medicaments: An in vitro study. J Int Oral Health. 2014;6(1):59-65.

26. Scatena C, Galafassi D, Gomes-Silva JM, Borsatto MC, Serra MC. In vitro erosive effect of pediatric medicines on deciduous tooth enamel. Braz Dent J. 2014;25(1):22-27.

27. Johansson AK, Sorvari R, Birkhed D, Meurman JH. Dental erosion in deciduous teeth - an in vivo and in vitro study. J Dent. 2001;29(5):333-340.

28. Shellis RP, Featherstone JD, Lussi A. Understanding the chemistry of dental erosion. Monogr Oral Sci. 2014;25:163-179.

29. Barbour ME, Parker DM, Allen GC, Jandt KD. Enamel dissolution in citric acid as a function of calcium and phosphate concentrations and degree of saturation with respect to hydroxyapatite. Eur J Oral Sci. 2003;111(5):428-433.

30. Attin T, Meyer K, Hellwig E, Buchalla W, Lennon AM. Effect of mineral supplements to citric acid on enamel erosion. Arch Oral Biol. 2003;48(11):753-759.

31. West NX, Hughes JA, Addy M. The effect of $\mathrm{pH}$ on the erosion of dentine and enamel by dietary acids in vitro. J Oral Rehabil. 2001;28(9):860-864.

32. Hunter M, West $N$, Hughes J, Newcombe R, Addy M. Erosion of deciduous and permanent dental hard tissues in the oral environment. J Dent. 2000;28(4):257-263.

33. Dawes $\mathrm{C}$. What is the critical $\mathrm{pH}$ and why does a tooth dissolve in acid? J Can Dent Assoc. 2003;69(11):722-724.

34. Hemingway CA, Parker DM, Addy M, Barbour ME. Erosion of enamel by non-carbonated soft drinks with and without toothbrushing abrasion. Br Dent J. 2006;201(7):447-450. 